\title{
Prognostic Value of Hypothalamic Copeptin in Acute Ischemic Stroke
}

\author{
Aktham Ismail Alemamª, ${ }^{\mathrm{a}}$, Mohamad Ezzat Elwanª ${ }^{\mathrm{a}}$ Ibrahim Alsayed Alahmar ${ }^{\mathrm{a}}$
}

\begin{abstract}
Background: Some studies showed that copeptin, a hypothalamic hormone derived from the precursor of vasopressin, may be useful in the prediction of outcome of ischemic cerebral stroke. The aim of this work was to search if there is any correlation between serum copeptin, in the first day of ischemic stroke, and its clinical severity, radiological findings and also its predictive value of functional outcome in these patients.
\end{abstract}

Methods: This study was conducted on 55 patients of both sexes with ischemic cerebral stroke admitted to Neurology Department, Menofyia University within 24 hours of the onset of ischemic stroke. Patients were subjected to general and neurological examination, laboratory assessment (routine and serum level of copeptin), and brain computerized tomography (CT), or magnetic resonance imaging (MRI). The anatomical site of stroke was evaluated by using the Oxford Community Stroke Project (OCSP) classification. The etiological subtypes of stroke were classified according to Trial of Organization 10172 in Acute Stroke Treatment (TOAST) classification. Stroke severity was evaluated by Scandinavian stroke scale (NIHSS) and disability by modified Rankin scale (MRS) at admission and at 30 days.

Results: The results showed high statistically significant correlation between the mean value of copeptin level and severity of stroke on admission $(\mathrm{P}<0.001)$, and also with the size of the infarction $(\mathrm{P}<$ $0.001)$. There was statistically significant difference $(P=0.011)$ of copeptin level among the studied groups regarding the site of stroke. Additionally, there was high statistically significant difference $(\mathrm{P}<$ 0.001 ) between copeptin level and the etiological subtypes of stroke. The favorable outcome of the stroke was with cutoff point of copeptin below $21.5 \mathrm{ng} / \mathrm{mL}$.

Conclusion: Serum copeptin may help in the prediction of severity of ischemic stroke, its size, site, etiological subtypes and functional outcome.

Manuscript accepted for publication April 12, 2016

${ }^{a}$ Neurology Department, Menoufiya School of Medicine, Egypt ${ }^{b}$ Corresponding Author: Aktham Ismail Alemam, Neurology Department, Menoufiya School of Medicine, Egypt. Email: e_aktham@yahoo.com

doi: http://dx.doi.org/10.14740/jnr377w
Keywords: Copeptin; Ischemic stroke; Prognosis

\section{Introduction}

Worldwide, stroke is the second most common cause of mortality and the third most common cause of disability [1]. In this context, rapidly measurable and reliable blood biomarkers may refine clinical decision-making. Several blood biomarkers have shown the potential to predict outcome after ischemic stroke. However, to be useful in clinical routine, blood biomarkers are expected to improve the prognostic accuracy of established clinical variables such as stroke severity and age [2].

Some studies showed that copeptin, a hypothalamic hormone derived from the precursor of vasopressin, predicted outcome and mortality of ischemic stroke [3, 4]. Argininevasopressin (AVP) is one of the main hormones of the hypothalamic-pituitary-adrenal axis. Its main stimulus for secretion is hyperosmolarity, but AVP system is also stimulated by exposure of the body to endogenous stress. Reliable measurement of AVP concentration is difficult because it is subject to pre-analytical and analytical errors. It is therefore not used in clinical practice. Activation of AVP system stimulates copeptin secretion into the circulation from the posterior pituitary gland in equimolar amounts with AVP. Therefore, copeptin directly reflects AVP concentration and can be used as a surrogate biomarker of AVP secretion [5].

The aim of this work was to search if there is any correlation between serum copeptin, in the first day of ischemic stroke, and its clinical severity, radiological findings and also its predictive value of functional outcome and mortality in these patients.

\section{Patients and Methods}

This study was conducted on 55 patients of both sexes with ischemic cerebral stroke admitted to the Neurology Department of Menoufiya University Hospitals. Their ages were ranging from 20 to 85 years, and their mean age was $52.41 \pm 15.30$ years. They were 17 females $(30.9 \%)$ and 38 males (69.1\%). Before starting the study, the ethics committee approved it and 
Table 1. Correlation Between Copeptin Level and Severity of Stroke According to NIHSS

\begin{tabular}{llll} 
NIHSS & Copeptin $($ mean \pm SD) & Test & Post hoc value \\
Mild (I) & $7.58 \pm 1.76$ & F $=207.46$ & $<0.001$ (I vs. II, I vs. III, I vs. IV, II vs. III, II vs. IV, III vs. IV) \\
Moderate (II) & $18.12 \pm 3.03$ & P value $<0.001$ & \\
Severe (III) & $26.50 \pm 2.39$ & & \\
Very severe (IV) & $36.0 \pm 2.23$ & & \\
\hline
\end{tabular}

the informed consents were obtained from the patients.

\section{Inclusion criteria}

Patients with first time ischemic stroke, in the first $24 \mathrm{~h}$, confirmed by neuroimaging were included.

\section{Exclusion criteria}

Patients with hemorrhagic stroke, history of old cerebral stroke by history or as seen on neuroimaging on admission, history of cerebral transient ischemic attacks, syndrome of inappropriate antidiuretic hormone secretion, diabetes insipidus, renal insufficiency (creatinine $>1.5 \mathrm{mg} / \mathrm{dL}$ ), severe sepsis, co-existent ischemic heart disease or heart failure, history of recent surgery or trauma during the preceding 2 months, or autoimmune diseases with or without immunosuppressive therapy were excluded.

\section{Data collection}

\section{Clinical assessment}

History and examination

The stroke condition was evaluated with detailed and careful history taking, general (to assess the risk factors) and neurological examination using stroke sheet.

Clinical assessment of stroke severity and disability

Patient's condition was assessed with clinical scales performed by the same examiner using National Institutes of Health
Stroke Scale (NIHSS) within the first $24 \mathrm{~h}$ of admission, and modified Rankin scale (MRS) after 3 months of admission.

\section{Laboratory assessment}

Blood samples were taken at admission before treatment.

Routine tests included complete blood picture, liver function tests (prothrombin time, activated partial thromboplastin time (aPTT), albumin, bilirubin and liver transaminases (SGOT and SGPT), kidney function tests (blood urea nitrogen and creatinine), random blood sugar, and erythrocyte sedimentation rate.

Copeptin levels were assessed in plasma in a blinded batch analysis by a new chemiluminescence sandwich immunoassay. According to Morgenthaler et al (2009), the normal concentration of copeptin in the blood circulation was $1-12 \mathrm{pmol} / \mathrm{L}$ [6].

\section{Radiological assessment}

Brain computerized tomography (CT) was done at admission, focusing on the early infarction signs (focal brain swelling, early hypodensity, attenuation of basal ganglia, or hyperdense artery sign) and excluding cerebral hemorrhage or any focal lesion. Follow-up brain CT was done to confirm the diagnosis of cerebral infarction. Brain magnetic resonance imaging (MRI) (when available) to determine the territory and the size of infarction, within $24 \mathrm{~h}$ of admission, was done.

The anatomical site of stroke was evaluated by using the Oxford Community Stroke Project classification (OCSP). It relies primarily on the initial symptoms, based on the extent of the symptoms. The stroke episode is classified as: total anterior circulation stroke (TAC), partial anterior circulation stroke (PAC), lacunar stroke (LAC) and posterior circulation stroke (POC).

The etiological subtypes of stroke were classified according to Trial of Organization 10172 in Acute Stroke Treatment

Table 2. Correlation Between Copeptin Level and Site of Stroke According to OCSP Classification

\begin{tabular}{llll}
\hline OCSP & Copeptin $($ mean \pm SD) & Test & Post hoc value \\
\hline PACS (I) & $17.70 \pm 8.58$ & Kruskal-Wallis $=11.11$ & I vs. II $=0.193$ \\
POCS (II) & $12.90 \pm 5.98$ & P value $=0.011$ & I vs. III $=0.783$ \\
LACS (III) & $15.70 \pm 6.98$ & & I vs. IV $=0.015$ (S) \\
TACS (IV) & $28.0 \pm 10.12$ & & II vs. III $=0.290$ \\
& & & II vs. IV $=0.004$ (S) \\
& & III vs. IV $=0.004$ (S) \\
\hline
\end{tabular}


Table 3. Correlation Between the Copeptin Level and Etiological Subtypes of Stroke According to TOAST Classification

\begin{tabular}{llll} 
TOAST & Copeptin $($ mean \pm SD) & Test & Post hoc value \\
\hline Cardio-embolic (I) & $12.15 \pm 6.24$ & Kruskal-Wallis $=21.19$ & I vs. II $<0.001(\mathrm{HS})$ \\
Large vessel (II) & $25.50 \pm 8.34$ & P value $<0.001$ & I vs. III $=0.092$ \\
Small vessel (III) & $15.83 \pm 6.79$ & & I vs. IV $=0.930$ \\
Cryptogenic (IV) & $12.0 \pm 6.0$ & & II vs. III $=0.002(\mathrm{~S})$ \\
& & & II vs. IV $=0.003$ (S) \\
\end{tabular}

Table 4. Correlation Between the Copeptin Level and Size of Stroke

\begin{tabular}{lllll}
\hline Lesion size & Copeptin $($ mean \pm SD) & Kruskal-Wallis & P value & Post hoc test \\
\hline$<1.5$ (I) (small) & $11.10 \pm 5.59$ & 18.89 & $\mathrm{P}<0.001$ & I vs. II $=0.006$ \\
$1.5-3$ (II) (medium) & $18.63 \pm 8.0$ & & I vs. III $<0.001$ \\
$>3$ (III) (large) & $24.05 \pm 8.36$ & & II vs. III $=0.047$ \\
\hline
\end{tabular}

(TOAST) classification. This system divides the ischemic stroke into atherothrombotic, cardioembolic, lacunar, undetermined etiology, and stroke of other etiology.

\section{Results}

The results showed that $87.3 \%(\mathrm{~N}=48)$ of the patients had the known risk factors of cerebral stroke, while $12.7 \%(\mathrm{~N}=7)$ of them had no ones. Hypertension was the most frequent one and it was present in $60.4 \%$ of patients $(\mathrm{N}=29)$, diabetes mellitus in $31.3 \%(\mathrm{~N}=15)$, atrial fibrillation in $25 \%(\mathrm{~N}=12)$, smoking in $18.2 \%(\mathrm{~N}=10)$, and dyslipidemia in $14.6 \%(\mathrm{~N}=7)$ of patients. The presence of multiple risk factors was in $68.8 \%$ $(\mathrm{N}=33)$ of them.

The site of stroke (using OCSP) was in PACS in $36.4 \%$ $(\mathrm{N}=20)$, in POCS in $18.2 \%(\mathrm{~N}=10)$, in LACS in $30.9 \%(\mathrm{~N}=$ $17)$, and in TACS in $14.5 \%(\mathrm{~N}=8)$ of the patients.

According to ischemic stroke etiological subtypes (using TOAST classification), stroke of cardioembolic origin was present in $23.6 \%(\mathrm{~N}=13)$, of large vessel origin in $32.7 \%(\mathrm{~N}=$ 18 ), of small vessel origin in $32.7 \%(\mathrm{~N}=18)$, and cryptogenic one in $10.9 \%(\mathrm{~N}=6)$ of the patients.

The size of infarction in neuroimaging study showed that stroke of small size $(<1.5 \mathrm{~cm})$ was present in $38.2 \%(\mathrm{~N}=21)$, of medium size $(1.5-3 \mathrm{~cm})$ in $34.5 \%(\mathrm{~N}=19)$, and of large size $(>3 \mathrm{~cm})$ in $37.3 \%(\mathrm{~N}=15)$ of the patients.

As regards to the clinical severity of ischemic stroke on admission (by NIHSS), mild stroke was present in $30.9 \%(\mathrm{~N}=$ $17)$, moderate stroke in $45 \%(\mathrm{~N}=25)$, severe stroke in $14.5 \%$ $(\mathrm{N}=8)$, and very severe stroke in $9.1 \%(\mathrm{~N}=5)$ of the patients.

According to stroke outcome 3 months after ischemic stroke (measured by MRS), no significant disability was in $5.45 \%(\mathrm{~N}=3)$, slight disability in $25.45 \%(\mathrm{~N}=14)$, moderate disability in $45.5 \%(\mathrm{~N}=25)$, moderate to severe disability in $7.27 \%(\mathrm{~N}=4)$, severe disability in $7.27 \%(\mathrm{~N}=4)$ of the patients, while $9.1 \%(\mathrm{~N}=5)$ of the patients died.

There was high statistically significant correlation be- tween the mean value of copeptin level and severity of stroke on admission $(\mathrm{P}<0.001)$ (Table 1$)$.

There was statistically significant difference $(\mathrm{P}=0.011)$ of the mean value of copeptin level among the studied groups regarding OCSP. It was lowest in patients with POCS (12.90 \pm $5.98)$ and highest in patients with TACS $(28.0 \pm 10.12)$ (Table 2).

There was high statistically significant difference ( $P$ $<0.001$ ) between the mean value of copeptin level and the etiological subtypes of stroke in the studied groups regarding TOAST classification. It was highest in the patients with large vessel stroke, and lowest in the patients with cryptogenic one (Table 3).

There was high statistically significant difference $(\mathrm{P}<$ 0.001 ) between the mean value of copeptin level among studied groups according to the size of the lesion. It was lowest in patients with small infarction, and highest in those with large infarction (Table 4).

The favorable outcome of the stroke was with cutoff point of copeptin below $21.5 \mathrm{ng} / \mathrm{mL}$ (Table 5).

\section{Discussion}

Many publications have reported an association of different biomarkers with stroke severity or outcome. These included CRP [7-9], IL-6 [2], matrix metalloproteinase-9 [10], fibrinogen [11], brain atriuretic peptide [12], and cortisol [13]. How-

Table 5. Relation Between the Outcome of Ischemic Stroke by MRS and Cutoff Point of Copeptin

\begin{tabular}{llll}
\hline \multirow{2}{*}{ Copeptin level } & \multicolumn{2}{c}{ Outcome } & Total \\
\cline { 2 - 3 } & Unfavorable & Favorable & \\
\hline 21.5 & 13 & 10 & 23 \\
\hline 21.5 & 0 & 32 & 32 \\
\hline Total & 13 & 42 & 55 \\
\hline
\end{tabular}


ever, none of these publications has reported that the analyzed biomarker increased the predictive power of validated clinical prognostic scores such as the NIHSS score [2]. To be an ideal marker for ischemia in the central nervous system, it should peak and accumulate early in the ischemic cascade, diffuse rapidly through ischemic tissue into the blood stream, have a half-life of at least a few hours and be specific for ischemic neural tissue [14].

In this study, we searched if there was a correlation between serum copeptin and stroke severity (using NIHSS), site (using OCSP), size (using CT and/or MRI brain), etiological subtypes (using TOST), and outcome (using MRS).

In our study, there was highly significant statistical correlation $(\mathrm{P}<0.001)$ between the mean value of copeptin level $(36.0 \pm 2.23)$ and very severe NIHSS.

This is in agreement with Khan et al [15], and Katan et al [16] who found that copeptin is a reliable prognostic marker in stroke patients. Also, Kyu-Sun et al [17] postulated that early measurement of plasma copeptin could provide better prognostic information for patients with acute stroke and help in decision making for therapeutic interventions.

Also, Urwyler et al [4] showed that copeptin may help in the prediction of outcome and mortality 3 months and 1 year after ischemic stroke [4].

Additionally, De Marchis et al [18] stated that copeptin represents a novel, reliable, and promising blood marker to predict stroke after transient ischemic attack (TIA), adding prognostic information.

In contrast to our results, Von Recum et al [19] found that there was no significant correlation between copeptin values and NIHSS in ischemic stroke patients. He compared values of copeptin and NIHSS in three groups of patients (ischemic stroke group, TIA group, and stroke mimics group).

Our study showed that serum copeptin had a significantly statistical correlation with the size of cerebral infarction. This coincides with Katan et al [3] who stated that in the 197 patients with cerebral infarction in whom MRI was available, copeptin levels paralleled lesion size. Median copeptin levels in patients with a small lesion were about half the levels in patients with medium lesions (8.4 (IQR: 4.4 - 13.7) vs. 14.9 (IQR: 6.6 - 26.0) pmol/L), whereas levels were greatest in patients with a large lesion (18.3 (IQR: 5.3 - 51.9) pmol/L).

Although the exact mechanism relating copeptin with unfavorable outcome and mortality in acute stroke is not fully understood, brain edema plays a critical role in the pathophysiology and morbidity [20]. In addition, data from experimental studies imply that vasopressin plays a role in brain edema formation and ischemic neuronal injury, as blocking of vasopressin receptors attenuates brain edema in ischemic and traumatic mice models [21]. In addition AVP/copeptin might be associated with adrenocorticotropic hormone-induced hypercortisolism, which is thought to potentiate ischemic neuronal injury [22]. Finally, copeptin is significantly increased in bacterial infection and febrile conditions. Early inflammation is very common and has been suggested as an important factor contributing to unfavorable prognosis after acute ischemic stroke [5].

AVP binds to three different receptors, V1a, V1b and V2 receptor. They are classified into three subtypes based on their intracellular transduction mechanisms. The V1a and V1b re- ceptors are associated with phosphoinositol turnover, while the $\mathrm{V} 2$ receptor activates adenylate cyclase [23]. The V1a receptor is widely expressed and mediates AVPs prothrombotic and vasoconstrictor effects [24]. The V1b receptor is expressed in the pituitary gland and pancreas [25]. Through this receptor AVP stimulates the release of adrenocorticotropic hormone. Adrenocorticotropic hormone activates the hypothalamic-pituitaryadrenal axis and thus mediates a response to stress.

Furthermore, Kyu-Sun et al [17] found that the elevation of plasma copeptin level may indicate that the patient required further evaluation, especially since copeptin is elevated in lifethreatening diseases such as shock, renal insufficiency, heart failure, acute myocardial infarction, hospital-acquired pneumonia, and pulmonary thromboembolism. Further studies may be needed to assess change in predictive value of serum copeptin with different treatment approaches as fibrinolytic therapy and mechanical thrombectomy. Also other studies could be done on large number of patients assessing serum copeptin in different types of cerebral strokes.

\section{Conclusion}

Copeptin appears to have an interesting potential as a new prognostic biomarker for patients with acute ischemic cerebral stroke. Early measurement of serum copeptin could help in the prediction of severity of ischemic stroke at admission and functional outcome 3 months later after ischemic stroke.

\section{References}

1. Lozano R, Naghavi M, Foreman K, Lim S, Shibuya K, Aboyans V, Abraham J, et al. Global and regional mortality from 235 causes of death for 20 age groups in 1990 and 2010: a systematic analysis for the Global Burden of Disease Study 2010. Lancet. 2012;380(9859):2095-2128.

2. Whiteley W, Chong WL, Sengupta A, Sandercock P. Blood markers for the prognosis of ischemic stroke: a systematic review. Stroke. 2009;40(5):e380-389.

3. Katan M, Fluri F, Morgenthaler NG, Schuetz P, Zweifel $\mathrm{C}$, Bingisser R, Muller K, et al. Copeptin: a novel, independent prognostic marker in patients with ischemic stroke. Ann Neurol. 2009;66(6):799-808.

4. Urwyler SA, Schuetz P, Fluri F, Morgenthaler NG, Zweifel C, Bergmann A, Bingisser R, et al. Prognostic value of copeptin: one-year outcome in patients with acute stroke. Stroke. 2010;41(7):1564-1567.

5. Jochberger S, Mayr VD, Luckner G, Wenzel V, Ulmer H, Schmid S, Knotzer H, et al. Serum vasopressin concentrations in critically ill patients. Crit Care Med. 2006;34(2):293-299.

6. Morgenthaler NG, Struck J, Jochberger S, Dunser MW. Copeptin: clinical use of a new biomarker. Trends Endocrinol Metab. 2008;19(2):43-49.

7. Di Napoli M, Papa F, Bocola V. Prognostic influence of increased C-reactive protein and fibrinogen levels in ischemic stroke. Stroke. 2001;32(1):133-138.

8. Elkind MS, Tai W, Coates K, Paik MC, Sacco RL. High- 
sensitivity C-reactive protein, lipoprotein-associated phospholipase A2, and outcome after ischemic stroke. Arch Intern Med. 2006;166(19):2073-2080.

9. Shantikumar S, Grant PJ, Catto AJ, Bamford JM, Carter AM. Elevated C-reactive protein and long-term mortality after ischaemic stroke: relationship with markers of endothelial cell and platelet activation. Stroke. 2009;40(3):977-979.

10. Kelly PJ, Morrow JD, Ning M, Koroshetz W, Lo EH, Terry E, Milne GL, et al. Oxidative stress and matrix metalloproteinase-9 in acute ischemic stroke: the Biomarker Evaluation for Antioxidant Therapies in Stroke (BEATStroke) study. Stroke. 2008;39(1):100-104.

11. del Zoppo GJ, Levy DE, Wasiewski WW, Pancioli AM, Demchuk AM, Trammel J, Demaerschalk BM, et al. Hyperfibrinogenemia and functional outcome from acute ischemic stroke. Stroke. 2009;40(5):1687-1691.

12. Whiteley W, Rumley A, Sattar N, Wardlaw JM, Lowe GDO, Welsh P, et al. POS11 blood markers and poor outcome after acute cerebrovascular disease: a prospective cohort study. J Neurol Neurosurg Psychiatry. 2010;81:e70.

13. Neidert S, Katan M, Schuetz P, Fluri F, Ernst A, Bingisser $\mathrm{R}$, et al. Anterior pituitary-axis hormones and outcome in acute ischemic stroke. J Intern Med. 2011;269:420-432.

14. Anand N, Stead LG. Neuron-specific enolase as a marker for acute ischemic stroke: a systematic review. Cerebrovasc Dis. 2005;20:213.

15. Khan SQ, Dhillon OS, O'Brien RJ, Struck J, Quinn PA, Morgenthaler NG, Squire IB, et al. C-terminal provasopressin (copeptin) as a novel and prognostic marker in acute myocardial infarction: Leicester Acute Myocardial Infarction Peptide (LAMP) study. Circulation. 2007;115(16):2103-2110.

16. Katan M, Christ-Crain M. The stress hormone copeptin: a new prognostic biomarker in acute illness. Swiss Med
Wkly. 2010;140:w13101.

17. Choi KS, Kim HJ, Chun HJ, Kim JM, Yi HJ, Cheong JH, $\mathrm{Kim} \mathrm{CH}$, et al. Prognostic role of copeptin after stroke: A systematic review and meta-analysis of observational studies. Sci Rep. 2015;5:11665.

18. De Marchis GM, Katan M, Weck A, Fluri F, Foerch C, Findling O, Schuetz $\mathrm{P}$, et al. Copeptin adds prognostic information after ischemic stroke: results from the CoRisk study. Neurology. 2013;80(14):1278-1286.

19. von Recum J, Searle J, Slagman A, Vollert JO, Endres M, Mockel M, Ebinger M. Copeptin: Limited Usefulness in Early Stroke Differentiation? Stroke Res Treat. 2015;2015:768401.

20. Manley GT, Fujimura M, Ma T, Noshita N, Filiz F, Bollen AW, Chan P, et al. Aquaporin-4 deletion in mice reduces brain edema after acute water intoxication and ischemic stroke. Nat Med. 2000;6(2):159-163.

21. Vakili A, Kataoka H, Plesnila N. Role of arginine vasopressin V1 and V2 receptors for brain damage after transient focal cerebral ischemia. J Cereb Blood Flow Metab. 2005;25(8):1012-1019.

22. Sapolsky RM. Stress, Glucocorticoids, and Damage to the Nervous System: The Current State of Confusion. Stress. 1996;1(1):1-19.

23. Egashira N, Mishima K, Iwasaki K, Oishi R, Fujiwara $\mathrm{M}$. New topics in vasopressin receptors and approach to novel drugs: role of the vasopressin receptor in psychological and cognitive functions. J Pharmacol Sci. 2009;109(1):44-49.

24. Seligman R, Seligman BG, Teixeira PJ. Comparing the accuracy of predictors of mortality in ventilator-associated pneumonia. J Bras Pneumol. 2011;37(4):495-503.

25. Enhorning S, Wang TJ, Nilsson PM, Almgren P, Hedblad B, Berglund G, Struck J, et al. Plasma copeptin and the risk of diabetes mellitus. Circulation. 2010;121(19):21022108 . 